\title{
BMJ
}

\section{Effect on birth outcomes of a formalised approach to care in hospital labour assessment units: international, randomised controlled trial}

\author{
Ellen D Hodnett, professor, ${ }^{1}$ Robyn Stremler, assistant professor, ${ }^{1,2}$ Andrew R Willan, senior scientist, ${ }^{2,3}$ Julie \\ A Weston, senior trial coordinator, ${ }^{1}$ Nancy K Lowe, professor, ${ }^{4}$ Kathleen R Simpson, clinical nurse \\ specialist, ${ }^{5}$ William D Fraser, professor, ${ }^{6}$ Amiram Gafni, professor, ${ }^{7}$ the SELAN (Structured Early Labour \\ Assessment and Care by Nurses) Trial Group
}

'Lawrence S Bloomberg Faculty of Nursing, University of Toronto, 155 College St, Toronto, ON, Canada, M5T 1P8

2Program in Child Health Evaluative Sciences, and Research Institute at SickKids, SickKids Hospital, Toronto, Canada

${ }^{3}$ Dalla Lana School of Public Health, University of Toronto, 155 College St, Toronto, ON, Canada, M5T 3M7

${ }^{4}$ University of Colorado Health Sciences Center, School of Nursing, Denver, CO, USA

${ }^{5}$ Labor and Delivery, St John's Mercy Medical Center, St Louis, MO, USA

${ }^{6}$ Université de Montréal, Département d'obstétriquegynécologie, Pavillon RogerGaudry, Montréal, QC, Canada

${ }^{7}$ Department of Clinical Epidemiology and Biostatistics, and Centre for Health Economics and Policy Evaluation, McMaster University, Hamilton, ON, Canada Correspondence to: E D Hodnett ellen.hodnett@utoronto.ca

Cite this as: $B M J$ 2008;337:a1021 doi:10.1136/bmi.a1021

\section{ABSTRACT}

Objective To determine if a complex nursing and midwifery intervention in hospital labour assessment units would increase the likelihood of spontaneous vaginal birth and improve other maternal and neonatal outcomes.

Design Multicentre, randomised controlled trial with prognostic stratification by hospital.

Setting 20 North American and UK hospitals.

Participants 5002 nulliparous women experiencing contractions but not in active labour; 2501 were allocated to structured care and 2501 to usual care.

Interventions Usual nursing or midwifery care or a minimum of one hour of care by a nurse or midwife trained in structured care, consisting of a formalised approach to assessment of and interventions for maternal emotional state, pain, and fetal position.

Main outcome measures Primary outcome was spontaneous vaginal birth. Other outcomes included intrapartum interventions, women's views of their care, and indicators of maternal and fetal health during hospital stay and 6-8 weeks after discharge.

Results Outcome data were obtained for 4996 women. The rate of spontaneous vaginal birth was $64.0 \%$ $(n=1597)$ in the structured care group and $61.3 \%$ $(n=1533)$ in the usual care group (odds ratio 1.12, 95\% confidence interval 0.96 to 1.27 ). Fewer women allocated to structured care $(n=403,19.5 \%)$ rated staff helpfulness as less than very helpful than those allocated to usual care $(n=544,26.4 \%)$; odds ratio $0.67,98.75 \%$ confidence interval 0.50 to 0.85 . Fewerwomen allocated to structured care $(n=233,11.3 \%)$ were disappointed with the amount of attention received from staff than those allocated to usual care $(n=407,19.7 \%)$; odds ratio $0.51,98.75 \%$ confidence interval 0.32 to 0.70 . None of the other results met prespecified levels of statistical significance.

Conclusion A structured approach to care in hospital labour assessment units increased satisfaction with care and was suggestive of a modest increase in the likelihood of spontaneous vaginal birth. Further study to strengthen the intervention is warranted.
Trial registration Current Controlled Trials ISRCTN16315180.

\section{INTRODUCTION}

Since the late 1980s labour assessment units have become a routine feature in North American hospitals, but they remain uncommon elsewhere. The original intent of such units was to restrict hospital admission to those who were judged to be in active labour or experiencing complications, in accordance with the tenets of "active management of labour." Care providers may pay little attention to variations in length of latent phase labour because of widespread beliefs that they are not associated with increased obstetrical risk. ${ }^{2}$ Latent phase labour may, however, involve painful contractions that occur intermittently for hours or days, and a prolonged latent phase may not be benign. Over 30 years ago the National Collaborative Perinatal Project reported an association between a prolonged latent phase and increased neonatal mortality and morbidity. ${ }^{3}$ A 1993 California study of more than 10000 term deliveries of babies at no previous risk found that a prolonged latent phase (defined as $>12$ hours for nulliparous women and $>6$ hours for multiparous women) was independently associated with a higher risk of abnormalities during labour, caesarean delivery, low Apgar score, and need for neonatal resuscitation. ${ }^{4}$ Although many factors may contribute to a prolonged latent phase, two problems consistently associated with it are high maternal anxiety and a malpositioned fetal head..$^{5-9}$ Thus the labour assessment unit offers an opportunity for both primary and secondary prevention of complications.

Several studies have found associations between anxiety before active labour and intrapartum complications. ${ }^{610-12}$ Women in latent labour who expressed negative feelings about their ability to cope or had high pain ratings were more likely to develop intrapartum complications. ${ }^{5}$ Reframing negative thoughts to positive ones may reduce anxiety and the likelihood of subsequent complications. Brief cognitive 


\section{Components of structured care}

The following components were taught in the training programme and used in the structured care group*

- Normalise the environment-if the labour assessment unit is a clinical environment or offers little privacy, move to a lounge or empty room away from medical equipment; encourage use of comforting objects and spontaneous self comforting behaviours

- Palpate to assess fetal position

- Encourage maternal positions that promote fetal head rotation or relieve pain-standing and leaning forward; asymmetrical upright (standing, kneeling, sitting); sitting upright; sitting, leaning forward with support; kneeling, leaning forward with support; on hands and knees; side lying positions (pure side lying and exaggerated Sims or semiprone); abdominal lifting

- Assess labour pain, both contraction pain and backache; assess physiological and behavioural indicators of pain; assess pain using a visual analogue scale

- Demonstrate cognitive, behavioural, and sensory interventions to manage labour pain; be present continuously; encourage comfort measures, including breathing and relaxation, application of heat and cold, massage, shower or bath, movement; encourage visualisation techniques, including recalling past experiences when contentment has been felt, picturing the results of the contractions (cervical dilation, fetal rotation, and descent), and visualising each contraction as a mountain and each breath as a step towards the peak; help create a ritual behaviour to use with each contraction; suggest music and rhythmic techniques

- Assess maternal emotional status; be aware of behavioural indicators of emotional distress; know how and when to ask direct questions, such as "What was going through your mind during that last contraction?" to identify coping related responses compared with distress related responses

- Use interventions to reduce emotional distress: offer helpful replies to distress related responses; reframe negative thoughts to positive ones; discuss the importance of relaxation, rhythm, and ritual; scan the body for areas of tension to focus relaxation efforts

- If hospital admission is not planned, discuss the importance of carrying on normal activities of daily living, with specific suggestions appropriate to time of day; offer anticipatory guidance about coping with labour as it becomes more active

"Content on positioning, interventions for pain, and assessment and interventions for emotional status was adapted from Simkin and Ancheta $1999^{24}$ intrapartum interventions have focused on active labour and have had little effect on the likelihood of caesarean delivery. ${ }^{223}$ Using a pragmatic design we determined the effects on the likelihood of spontaneous vaginal birth of a formalised approach to care in labour assessment units, which focused on assessment of and anticipatory guidance on cognitive-emotional state, pain, and fetal position.

\section{METHODS}

The study was a multicentre, randomised controlled trial with prognostic stratification by hospital. Before the trial a group of nurses or midwives at each hospital were trained in the structured approach, with the number trained at each site reflecting the projected rate of enrolment. Additional training sessions were held during the recruitment phase in sites with substantial staff turnover. In the North American hospitals the two day training programme was carried out by nurse experts who worked in an organisation providing continuing education to labour nurses in Ontario, Canada. In the UK hospitals the training programme was carried out by an expert midwife instructor after consultation with the Canadian trainers, using an adaptation of the North American curriculum. At the end of the workshop each participant was given a manual, which reiterated course content and provided opportunities for the techniques to be practised before the onset of the trial. The box details the topics in the training programme, and the accompanying manual covered the components of structured care.

Throughout the trial providers of structured care could communicate with the trainers and with each other on an electronic listserv. Before the launch of the trial at each centre the principal investigator $(\mathrm{EH})$ held meetings with the staff at which she emphasised the uncertainty about the value of structured care and the importance of staff continuing to provide usual care to the control group, to maintain distinctions between both groups. explanations and reassurance that are part of routine clinical practice in outpatient settings and have shown efficacy in reducing anxiety and pain. ${ }^{1314}$

Malposition of the fetal head has been associated with a prolonged latent phase, increased pain, higher maternal anxiety, complications in active labour, and higher rates of operative delivery. ${ }^{15-18}$ Medical interventions during active labour, such as amniotomy, oxytocin, and epidural analgesia can be effective treatments for the problems resulting from malposition, but they do not increase the likelihood that the fetal head will rotate to the occiput anterior position. ${ }^{19}$ Simple positioning techniques may encourage rotation and descent. ${ }^{15}$

Caesarean delivery rates continue to increase. ${ }^{20}$ Although there has been some debate about whether women have the right to choose elective caesarean delivery, spontaneous vaginal birth is widely regarded as the safest method of birth for healthy mothers and babies at low risk. ${ }^{21}$ Controlled evaluations of

\section{Eligibility criteria}

To be eligible to participate the hospitals had to have a pre-existing, geographically distinct labour assessment unit and a spontaneous vaginal birth rate of $75 \%$ or less. In all study sites the labour assessment units were the entry points for women who thought they were in labour. In North America the units were staffed by nurses and in the UK by midwives, but the approach to care was the same-that is, the purpose was to determine whether a woman should be admitted to the labour ward or sent home to await active labour. Women were eligible for the study if they were nulliparous, had a live singleton fetus in the cephalic position, had no contraindications to labour, were competent to give informed consent or had a parent or guardian who was competent to give informed consent, and were experiencing contractions but did not meet labour ward criteria for admission. Women were not eligible if the gestational age was less than 34 weeks, an induction of labour or caesarean delivery was planned, 
they had complications that necessitated hospital admission, they were likely to be transferred to the labour ward within one hour, or they had a doula or midwife providing continuous support.

\section{Treatment protocol}

After basic assessment of labour (duration and frequency of contractions, status of membranes, status of the fetal heart rate, and assessment of cervical dilation as per hospital protocol) the women were assessed for trial eligibility. Baseline data were obtained after eligible women gave written, informed consent to participate and before randomisation. Determination of race or ethnicity was a combination of self assignment and observer assignment. Randomisation was centrally controlled and concealed, using an internet based service. The nurse or midwife accessed the trial website to obtain the participant's study group allocation.

Immediately after randomisation women assigned to the experimental group received one to one care by a nurse or midwife trained in structured care. The structured care provider palpated the participant's abdomen to assess fetal position and asked her to describe her thoughts during the last contraction and to rate pain intensity on a visual analogue scale. The provider used positioning techniques, comfort measures, and simple cognitive restructuring techniques such as positive visual imagery and reframing negative thoughts, and offered anticipatory guidance about coping with active labour (see box). If the woman was sent home without having delivered and if circumstances permitted, the provider was to telephone her later to check on her progress. When the woman returned, efforts were made to repeat structured care.

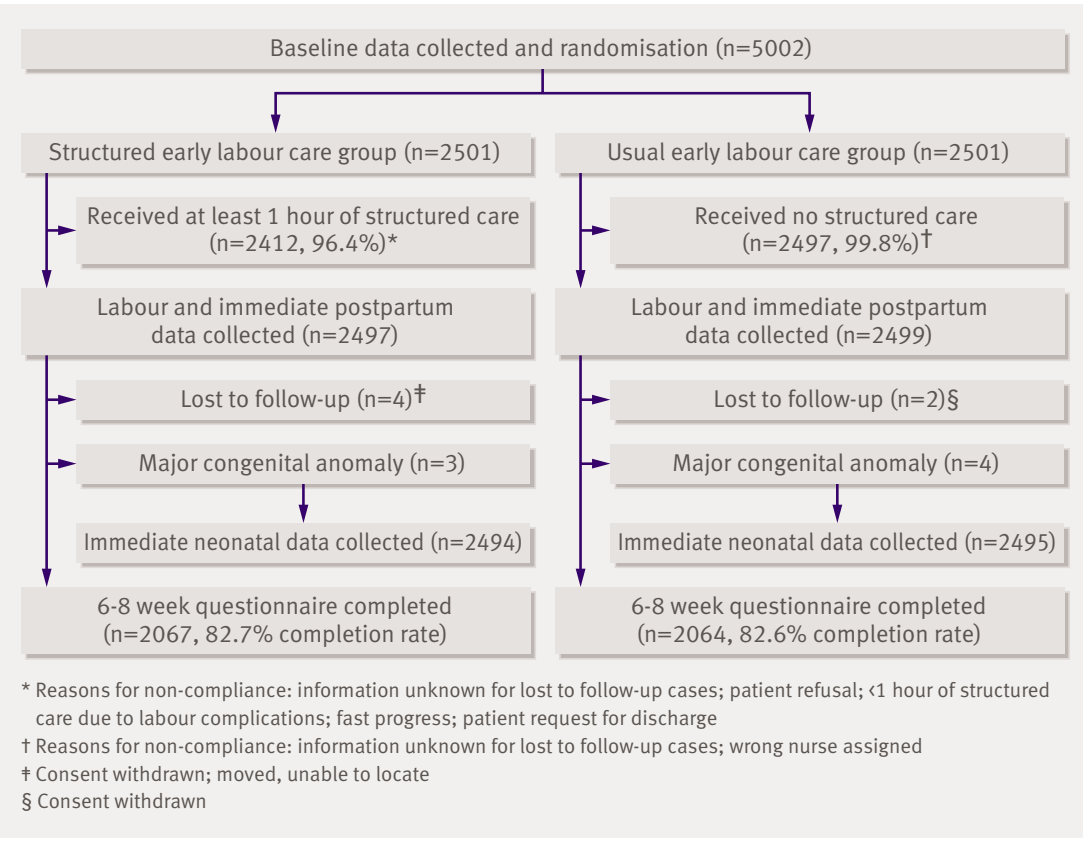

Flow diagram for trial
Women assigned to the control group received care by a nurse or midwife who had not been trained in structured care. One nurse or midwife often provided care to more than one woman. Usual care depended on many factors, including the provider's workload, the provider's knowledge of and beliefs about assessments of fetal position and cognitive-emotional state, and familiarity with appropriate interventions. Women who were sent home were advised to telephone the unit if they had any questions or concerns.

The length of time women received structured care or usual care was designed to reflect the usual time spent by women in labour assessment units (1-4 hours). In both groups the decision on whether to admit women to the labour ward or to send them home was made as per usual hospital policy. Labour assessment units offer varying degrees of privacy and in some settings it was possible that a patient randomised to the control group could overhear or witness parts of the care to a woman in the experimental group. Therefore no woman was invited to participate while a trial participant was in the labour assessment unit unless complete privacy could be assured. Only the nature of the nursing or midwifery care in the labour assessment unit varied between groups; all other care in the labour assessment unit and labour ward was in accordance with usual hospital practices and policies.

\section{Compliance}

Centres were instructed not to randomise women unless providers of both usual care and structured care were available. Structured care providers could care for non-study women but not for women in the control group. Usual care providers could not care for women in the structured care group. Compliance was assessed in two ways. We expected that over $90 \%$ in each group would receive their assigned method of care (care from a provider trained or not trained in structured care) immediately after randomisation. In addition, providers' reports of their care for women in the structured care group provided evidence of adherence to the main components of the intervention.

\section{Outcomes}

The primary outcome was spontaneous vaginal birth. Secondary outcomes were the number of women who had no intrapartum analgesia or anaesthesia, had perineal trauma requiring suturing, and reported negative views of their care (a subsequent paper will report on costs). Other study outcomes included the number of women with more than two visits for assessment of labour; use of intrapartum oxytocics, regional analgesia, and electronic fetal heart rate monitoring; length of hospital stay; and indicators of short term and longer term maternal and neonatal morbidity that have been linked in previous research to method of delivery, including postnatal emotional distress, readmission to hospital of mother or baby for delivery related complications in the first $6-8$ weeks after birth, neonatal transfer to a special care baby unit, and intrapartum fetal death or neonatal death. 
Table 1| Baseline characteristics of women in structured care and usual care groups. Values are numbers (percentages) unless stated otherwise

\begin{tabular}{|c|c|c|}
\hline Characteristic & Structured care $(n=2501)$ & Usual care $(n=2501)$ \\
\hline $\begin{array}{l}\text { Mean (SD, minimum-maximum) age } \\
\text { (years) }\end{array}$ & $26.7(5.87,14-45)$ & $26.6(5.95,15-44)$ \\
\hline \multicolumn{3}{|l|}{ Race or ethnicity: } \\
\hline White & $1693(67.7)$ & $1704(68.1)$ \\
\hline Black & $197(7.9)$ & $202(8.1)$ \\
\hline Latin American & $264(10.6)$ & $257(10.3)$ \\
\hline Chinese & $63(2.5)$ & $62(2.5)$ \\
\hline Japanese & $6(0.2)$ & $5(0.2)$ \\
\hline Korean & $12(0.5)$ & $11(0.4)$ \\
\hline South and South East Asian & $191(7.6)$ & $174(7.0)$ \\
\hline West Asian & $58(2.3)$ & $58(2.3)$ \\
\hline Aboriginal & $9(0.4)$ & $21(0.8)$ \\
\hline More than one race & $7(0.3)$ & $5(0.2)$ \\
\hline Unknown & $1(0.04)$ & $2(0.1)$ \\
\hline \multicolumn{3}{|l|}{ Education: } \\
\hline Lower than high school & $263(10.5)$ & $268(10.7)$ \\
\hline Completed high school & $793(31.7)$ & $799(32.0)$ \\
\hline Post-secondary & $1398(55.9)$ & $1377(55.1)$ \\
\hline Unknown & $47(1.9)$ & $57(2.3)$ \\
\hline Married or stable relationship & $2164(86.5)$ & $2138(85.5)$ \\
\hline \multicolumn{3}{|l|}{ No (\%) completed weeks of gestation: } \\
\hline$<34$ & $1(0.04)$ & $0(0.0)$ \\
\hline 34-36 & $201(8.0)$ & $172(6.9)$ \\
\hline $37-40$ & $2123(84.9)$ & $2158(86.3)$ \\
\hline$\geq 41$ & $176(7.0)$ & $171(6.8)$ \\
\hline Diabetes mellitus & $2(0.1)$ & $0(0.0)$ \\
\hline Hypertension & $54(2.2)$ & $57(2.3)$ \\
\hline No prenatal care & $9(0.4)$ & $8(0.3)$ \\
\hline \multicolumn{3}{|l|}{ Established labour: } \\
\hline Yes & $371(14.8)$ & $373(14.9)$ \\
\hline No & $1140(45.6)$ & $1098(43.9)$ \\
\hline Uncertain & $990(39.6)$ & $1030(41.2)$ \\
\hline \multicolumn{3}{|l|}{ Cervical dilation $(\mathrm{cm})$ : } \\
\hline 0 & $220(8.8)$ & $215(8.6)$ \\
\hline 1 & $829(33.2)$ & $809(32.4)$ \\
\hline 2 & $702(28.1)$ & $670(26.8)$ \\
\hline 12 & $248(9.9)$ & $258(10.3)$ \\
\hline Not assessed & $502(20.1)$ & $549(22.0)$ \\
\hline Ruptured membranes & $68(2.7)$ & $58(2.3)$ \\
\hline $\begin{array}{l}\text { Previous admission for labour } \\
\text { assessment }\end{array}$ & $556(22.2)$ & $590(23.6)$ \\
\hline
\end{tabular}

Percentages may not sum to 100 owing to rounding or missing data.

Trained research nurses or midwives at each hospital abstracted relevant data from the medical records and entered the data into study forms on the trial website. Because the data collection included a question about compliance (whether a provider with training in structured care had cared for the participant), the research staff may not have been fully blinded during retrieval of data from the medical records. The primary and other medical outcomes were, however, objective data that were recorded in the medical records as part of routine practice. Audits of medical records at selected sites during the enrolment period showed neither systematic errors nor important random errors.
Attending doctors were not explicitly informed of their patients' group assignments and were rarely present in labour assessment units.

Participants were asked to complete a questionnaire 6-8 weeks after the birth, which focused on their health, their baby's health, and their satisfaction with care. The questionnaire included the Edinburgh postnatal depression scale; a score greater than 12 is a reliable indicator of postnatal depressive symptomatology. ${ }^{25}$ Measurement of satisfaction is problematic because of the "what is, must be best" phenomenon. ${ }^{2627} \mathrm{~A}$ systematic review identified key factors influencing satisfaction with childbirth, ${ }^{27}$ and the questionnaire items were adapted from one of the most reliable and well validated population based surveys of satisfaction with childbirth. ${ }^{28}$ Participants could complete their questionnaires directly on the secure trial website,${ }^{29}$ by post, or by telephone with the centre research nurse or midwife.

\section{Sample size calculation}

During development of the trial protocol 10 hospitals provided the rates of spontaneous vaginal birth for women who would meet trial eligibility criteria. Rates ranged from $42 \%$ to $76 \%$ (mean rate $58 \%$ ). In selecting the clinically important difference for the current trial we wanted to detect a $4 \%$ absolute difference in spontaneous vaginal birth rate-for example, eliminating one operative delivery for every 25 women treated. With a two sided $\alpha<0.05$ and $\alpha=0.20$ in hospitals at the extremes of the range, and when using the mean rate and taking the most conservative approach, we needed a sample size of 4932 . The target sample size was 5000 .

\section{Statistical analysis}

We analysed the results according to intention to treat. For the primary outcome we used a significance level of 0.05 (two tailed). We set the significance level for secondary outcomes at 0.0125 and for other study outcomes at 0.005 . Because we expected variation owing to the effects of unknown characteristics of the hospitals, the analytical approach allowed the proportion of women experiencing spontaneous vaginal birth and treatment effects to vary between hospitals. For binary outcome variables we compared the groups using a logistic regression model with a random hospital effect for the intercept and slope. We present the odds ratios and accompanying confidence intervals (corresponding to the preset $\mathrm{P}$ values for primary, secondary, and "other" outcomes). We used a similar logistic regression model to explore the interaction effects between baseline variables and treatment group on the primary outcome. For length of hospital stay we analysed data using a linear regression model with a random hospital effect for the intercept and slope, using the $\log$ of length of stay as the dependent variable. Statistical procedures were done using SAS version 9.1. For ratings of women's views of their care we followed the standard practice of comparing the frequencies with which less than very positive views were reported..$^{26-28}$ 


\section{RESULTS}

Twenty tertiary care teaching and community hospitals participated in the trial, eight in Canada, 10 in the United States, and two in the UK. Training in structured care was provided to 505 nurses and midwives; the remaining 1351 were available to provide usual care. The annual birth census at the hospitals ranged from 1200 to 9841 . Although the labour assessment units were separate from the labour wards, they varied in design, size, and staffing, from multibed rooms with beds separated by curtains, which were staffed on a rotating basis by nurses or midwives, to private rooms in units with staff who worked only in the labour assessment unit.

We enrolled 5002 women between 1 May 2003 and 6 March 2007 (figure). For reasons of cost and feasibility, data were not collected on eligible women who did not participate in the trial. Centre staff, however, stated that women rarely refused to participate; those who did stated that they had been informed of the study just before being sent home from the labour assessment unit and did not want to delay their departure. The main reasons for failure to enrol eligible women were logistical, including staff workload, unavailability of a provider for structured care, or the presence in the unit of a trial participant.

Table 1 shows the baseline characteristics of the sample. Immediately after randomisation the appropriate form of care was provided to 2412 of 2501 women $(96.6 \%)$ in the structured care group and to 2497 of 2501 women $(99.8 \%)$ in the usual care group. Structured care providers completed forms describing

Table 2 | Indicators of labour progress from randomisation until admission to labour ward. Values are numbers (percentages) unless stated otherwise

Indicator Structured care $(n=2497)$ Usual care $(n=2499)$

Total hours in labour assessment unit after randomisation*:

\begin{tabular}{lcc}
\hline Mean (SD) & $3.2(2.5)$ & $3.0(2.8)$ \\
\hline Median (interquartile range) & $2.5(1.5-4.0)$ & $2.1(1.0-3.9)$ \\
\hline No of times discharged undelivered: & & $1145(45.8)$ \\
\hline 0 & $1171(46.9)$ & $969(38.8)$ \\
\hline 1 & $964(38.6)$ & $265(10.6)$ \\
\hline 2 & $245(9.8)$ & $119(4.8) \dagger$ \\
\hline 2
\end{tabular}

Stage of labour immediately before transfer to

labour and delivery:

\begin{tabular}{lcc} 
Not established & $364(14.6)$ & $366(14.7)$ \\
\hline Early & $1061(42.5)$ & $1106(44.3)$ \\
\hline Active & $953(38.2)$ & $909(36.4)$ \\
\hline 2nd stage & $19(0.8)$ & $16(0.6)$ \\
\hline Unsure & $97(3.9)$ & $101(4.0)$
\end{tabular}

Cervical dilation immediately before transfer to

labour and delivery $(\mathrm{cm})$ :

\begin{tabular}{lcc}
\hline 3 & $808(32.4)$ & $837(33.5)$ \\
\hline $3-6$ & $1146(45.9)$ & $1148(45.9)$ \\
\hline 16 & $100(4.0)$ & $91(3.6)$ \\
\hline Not assessed & $440(17.6)$ & $422(16.9)$
\end{tabular}

*Includes cumulative time for those who had more than one visit.

†A secondary outcome (odds ratio $0.94,98.75 \%$ confidence interval 0.53 to 1.34 ). their activities for 2406 of the 2497 women in the structured care group (96.4\%). The forms provided evidence of the consistency with which the components of the intervention were provided. For example, in the first episode of structured care, fetal position, maternal emotional state, and intensity of pain were assessed in over $99 \%(\mathrm{n}=2402)$ of women in the structured care group. One or more structured care interventions were provided to all but seven women $(99.8 \%)$.

Table 2 compares the amount of time spent by the two groups in the labour assessment unit and provides indicators of labour progress before admission to the labour ward. The groups were similar on all indicators.

\section{Outcomes}

Primary and secondary outcomes

The rate of spontaneous vaginal birth was $64.0 \%$ $(n=1597)$ in the structured care group and $61.3 \%$ $(\mathrm{n}=1533)$ in the usual care group (odds ratio 1.12, 95\% confidence interval 0.96 to 1.27 ; table 3 ). The groups were comparable for women who had no intrapartum analgesia or anaesthesia and for those requiring suturing for perineal trauma (table 3 ). Women in the structured care group were less likely to report disappointment with both the amount of attention received from and the helpfulness of care providers in the labour assessment unit (table 4).

\section{Other immediate maternal outcomes}

Comparable numbers of women in both groups were sent home from the labour assessment unit on more than two occasions. In the structured care group $84.6 \%$ $(n=2112)$ of women had regional analgesia, compared with $86.4 \%(n=2159)$ in the usual care group. The rate of caesarean delivery in the structured care group was $22.4 \%(\mathrm{n}=559)$, compared with $24.2 \%(\mathrm{n}=604)$ in the usual care group. One maternal death occurred due to haemorrhage from a uterine artery after caesarean delivery. Other immediate maternal outcomes, including complications and length of postnatal hospital stay, were comparable in both groups.

\section{Immediate neonatal outcomes}

Because major congenital anomalies influence use of resuscitation and higher level of care as well as length of stay, data from seven babies (three in the structured care group, four in the usual care group) with major congenital anomalies were excluded from analyses of neonatal outcomes (table 5). One stillbirth and no neonatal deaths occurred. Just under 7\% of the sample $(n=339)$ required higher level care in a special care baby unit.

\section{Mothers' and babies' health 6-8 weeks after discharge} In total $76.0 \%(\mathrm{n}=1570)$ of mothers in the structured care group rated their general health as excellent or very good compared with $74.7 \%(n=1542)$ in the usual care group. One hundred and thirty four (6.5\%) mothers in the structured care group scored more than 12 on the Edinburgh postnatal depression scale, 
Table 3 | Comparisons of maternal outcomes from randomisation until postnatal hospital discharge. Values are numbers (percentages) of women unless stated otherwise

\begin{tabular}{|c|c|c|c|}
\hline Event & Structured care $(n=2497)$ & Usual care $(n=2499)$ & Odds ratio (Cl) \\
\hline \multicolumn{4}{|l|}{ Labour onset: } \\
\hline Spontaneous & $2232(89.4)$ & 2209 (88.4) & - \\
\hline Induced & $255(10.2)$ & $283(11.3)$ & - \\
\hline No labour & $8(0.3)$ & $6(0.2)$ & - \\
\hline Oxytocin started after active labour & $1553(62.2)$ & $1587(63.5)$ & $0.95(0.77 \text { to } 1.12)^{\star}$ \\
\hline \multicolumn{4}{|l|}{ Analgesia or anaesthesia†: } \\
\hline Regionalł & $2112(84.6)$ & $2159(86.4)$ & $0.85(0.62 \text { to } 1.08)^{\star}$ \\
\hline Intramuscular or intravenous opioid & $1126(45.1)$ & $1078(43.2)$ & - \\
\hline Nitrous oxide & $167(6.7)$ & $146(5.8)$ & - \\
\hline Pudendal, paracervical, saddle block & $8(0.3)$ & $4(0.2)$ & - \\
\hline General & $16(0.6)$ & $22(0.9)$ & - \\
\hline Other§ & $6(0.2)$ & $2(0.1)$ & - \\
\hline None & $112(4.5)$ & $112(4.5)$ & $1.06(0.54 \text { to } 1.58)^{\star}$ \\
\hline Continuous electronic fetal heart rate monitoring & $2117(84.8)$ & $2160(86.4)$ & $0.84(0.59 \text { to } 1.08)^{\star}$ \\
\hline \multicolumn{4}{|l|}{ Method of delivery: } \\
\hline Spontaneous vaginal delivery & $1597(64.0)$ & $1533(61.3)$ & $1.12(0.96 \text { to } 1.27)^{\star}$ \\
\hline Instrumental vaginal delivery & $341(13.7)$ & $362(14.5)$ & - \\
\hline Vacuum & 231 & 240 & - \\
\hline Forceps (low or mid) & 110 & 122 & - \\
\hline Caesarean delivery & $559(22.4)$ & $604(24.2)$ & $0.90(0.71 \text { to } 1.10)^{\star}$ \\
\hline Perineal trauma requiring suturing: & $1336(53.5)$ & $1350(54.0)$ & $0.98(0.82 \text { to } 1.13)^{*}$ \\
\hline Episiotomy & 569 & 573 & - \\
\hline Second degree laceration & 764 & 790 & - \\
\hline Third or fourth degree laceration & 131 & 111 & - \\
\hline Other & 3 & 0 & - \\
\hline Maternal death & $1 \pi$ & 0 & - \\
\hline \multicolumn{4}{|l|}{ Health problems during postnatal stay: } \\
\hline Postnatal fever & $24(1.0)$ & $23(0.9)$ & - \\
\hline Haemorrhage $>1000 \mathrm{ml}$ & $51(2.0)$ & $49(2.0)$ & - \\
\hline Transfusion given & $13(0.5)$ & $7(0.2)$ & - \\
\hline Other** & $10(0.4)$ & $4(0.2)$ & - \\
\hline $\begin{array}{l}\text { Length of postnatal hospital stay, median (interquartile range), } \\
\text { hours }\end{array}$ & $50.1(41.4,63.5)$ & $50.3(41.2,64.1), P=0.75 \neq \ddagger$ & - \\
\hline
\end{tabular}

*Spontaneous vaginal delivery was primary outcome; prespecified confidence interval $95 \%$. Oxytocin, regional analgesia, electronic fetal heart rate monitoring, and caesarean delivery were "other" outcomes; prespecified confidence interval $99.5 \%$. Perineal trauma requiring suturing was a secondary outcome; prespecified confidence interval $98.75 \%$. †Some women had more than one form of analgesia or anaesthesia.

$\ddagger$ Epidural analgesia, combined spinal anaesthesia and epidural, or spinal anaesthesia.

§Sterile water injections $(n=7)$ and intrathecal opioid $(n=1)$.

TDue to undetected haemorrhage from uterine artery after caesarean delivery. Data safety and monitoring committee concluded that death was unrelated to the trial.

${ }_{\star}^{*}$ Such as hospital acquired pneumonia; severe pregnancy induced hypertension; septic pelvic thrombophlebitis; severe endometriosis; major delivery complications (tear of smal bowel, cystostomy, bladder tear, severe bleeding requiring laparotomy, hysterectomy).

技respecified "other" outcome.

compared with $149(7.2 \%)$ in the usual care group (odds ratio $0.84,99.5 \%$ confidence interval 0.36 to 1.32 ). Most mothers rated their baby's health as excellent or very good $(95.7 \%$ in the structured care group, $94.9 \%$ in the usual care group). Forty four women in the structured care group and 37 women in the usual care group were readmitted for delivery related complications (odds ratio 1.19,99.9\% confidence interval 0.34 to 2.04). Sixty six babies in the structured care group and 83 in the usual care group were readmitted $(0.78,0.37$ to 1.20$)$.

\section{Secondary analyses}

Completion of some form of post-secondary education and being unmarried were associated with lower probabilities of a spontaneous vaginal birth, whereas being in established labour at trial entry and allocation to structured care were associated with higher probabilities of a spontaneous vaginal birth. In the regression model for main effects the odds ratio $(95 \%$ confidence intervals) for post-secondary education was 0.82 (0.70 to 0.93$)$, for being unmarried was $0.76(0.61$ to 0.91 ), for established labour was 1.25 (1.02 to 1.47$)$, and for allocation to structured care was 1.12 (1.00 to 1.26). When interaction terms involving treatment group and education, marital status, and established labour were entered into the model, $\mathrm{P}$ values were greater than 0.10

\section{DISCUSSION}

We evaluated a structured approach to nursing or midwifery care in hospital labour assessment units, 
Table 4 | Comparisons of women's reports of negative views of their care. ${ }^{\star}$ Values are numbers (percentages)

\begin{tabular}{|c|c|c|c|}
\hline Item & $\begin{array}{l}\text { Structured care } \\
\quad(n=2067)\end{array}$ & $\begin{array}{l}\text { Usual care } \\
(n=2064)\end{array}$ & Odds ratio $(\mathrm{Cl})$ \\
\hline \multicolumn{4}{|l|}{$\begin{array}{l}\text { Helpfulness of nurse or midwife in labour } \\
\text { assessment unit: }\end{array}$} \\
\hline Response other than "very helpful" & $403(19.5)$ & $544(26.4)$ & $0.67(0.50$ to 0.85$) \dagger$ \\
\hline \multicolumn{4}{|l|}{$\begin{array}{l}\text { Attention from staff in labour assessment } \\
\text { unit }\end{array}$} \\
\hline Unhappy with amount & $233(11.3)$ & $407(19.7)$ & $0.51(0.32$ to 0.70$) \dagger$ \\
\hline
\end{tabular}

*Of 4131 women who completed postnatal questionnaire.

†Secondary outcome; prespecified confidence interval $98.75 \%$.

which included assessment of and interventions for maternal emotional state, fetal position, and pain, during a minimum of one hour. With the important exception of women's views of their care (which favoured the structured care group), results did not reach conventional levels of statistical significance. The trend towards increased likelihood of spontaneous vaginal birth suggests that further refinement of structured care is warranted. Although logistic regression analyses found associations between spontaneous vaginal birth and marital status, education, and being in established labour at trial entry, we found no evidence that the between treatment comparisons for spontaneous vaginal birth differed between subgroups defined by these baseline variables.

Compliance was excellent, and reports from the providers of structured care indicated that the intervention was applied appropriately and consistently across and within sites. In this large multicentre trial it would have been prohibitively expensive to directly observe the providers' actions. We took several measures to prevent contamination. Throughout the trial we emphasised the importance of maintaining distinct study groups and the uncertainty of the value of the experimental approach. Staff providing structured care were volunteers who were favourably disposed towards the type of care. Staffing was such that usual care rarely allowed for one to one attention for 1-4

Table $5 \mid$ Comparisons of immediate neonatal outcomes. ${ }^{\star}$ Values are numbers (percentages) unless stated otherwise

\begin{tabular}{|c|c|c|}
\hline Characteristic & Structured care $(n=2494)$ & Usual care* $(n=2495)$ \\
\hline Alive at birth & $2494(100)$ & $2494(99.9) \dagger$ \\
\hline Girl & $1249(50.1)$ & $1288(51.6)$ \\
\hline Boy & 1245 (49.9) & $1207(48.4)$ \\
\hline Mean (SD) birth weight (g) & $3394(431)$ & 3404 (435) \\
\hline \multicolumn{3}{|l|}{ Apgar score <7: } \\
\hline 1 minute & $246(9.9)$ & $234(9.4)$ \\
\hline 5 minutes & $30(1.2)$ & $28(1.1)$ \\
\hline Neonatal death & 0 & 0 \\
\hline Higher level of care & $168(6.7)$ & $171(6.9)$ \\
\hline
\end{tabular}

hours, as required in structured care. As with our previous trial of another complex labour intervention in which blinding was impossible, ${ }^{23}$ we have indirect evidence that treatment fidelity was maintained. Women's evaluations of the helpfulness of and amount of attention received from staff were more favourable in the structured care group (table 4). Furthermore the hospital that enrolled the largest number of women to the trial (970) also had the highest risk of contamination; it was a self contained unit staffed by two nurses on each shift and yet its odds ratio for spontaneous vaginal birth was statistically significant $(1.34,95 \%$ confidence interval 1.03 to 1.75 ).

Complex interventions such as structured care have the advantage of mirroring the real world of practice, in which assessments and interventions are tailored to individual needs. Furthermore, synergistic effects among components of an intervention would be lost if each were evaluated individually. ${ }^{30}$ However, complex interventions have the disadvantage of leaving some uncertainty about the importance of each component of the intervention. ${ }^{31}$ Our approach reflected current best practice guidelines, by addressing context, collecting the best evidence, developing a conceptual model to explain the links between intervention components and outcome, and standardising the intervention. ${ }^{3032}$ None the less, the labour assessment units did not seem to delay admission to the labour ward, as nearly $60 \%$ of participants $(n=2897)$ were not in active labour when admitted (table 2).

Two early trials on labour have addressed the question of location of care. ${ }^{3334}$ One trial enrolled 209 women in one hospital in Ontario and randomised them to either a labour assessment unit or direct admission to the labour ward. ${ }^{34}$ The other trial enrolled 1459 women in seven hospitals in British Columbia (Canada) and randomised them to care either at home or in hospital. ${ }^{33}$ We evaluated an approach to the content (rather than the place) of care. Given the low intensity of the intervention, the absence of evidence of risk, the potential population effects if it were adopted, the continuing rise in caesarean delivery rates, and the beneficial effect on satisfaction with care, hospitals that already have labour assessment units may want to consider incorporating structured care into routine practice.

A combination of structured care plus strict adherence to a policy of delayed admission to the labour ward until clinically indicated may yield greater benefits. Questions remain about the optimum setting for women in latent phase labour and about the characteristics of hospitals that influence the effectiveness of forms of intrapartum nursing or midwifery care. Further research is warranted, given the paucity of effective interventions to increase the likelihood of spontaneous vaginal birth in healthy childbearing women.

We thank the participants, staff at the participating hospitals, and the structured care trainers (Melrose East, Adele Hood, Debbie Kaye, Debbie Patrick, Anne Simmonds, Ann Sprague, and Marie-Josée Trépanier); members of the Data Safety Monitoring Committee-Rona McCandlish 


\section{WHAT IS ALREADY KNOWN ON THIS TOPIC}

Prolonged latent phase labour is associated with increased risk of operative delivery and neonatal morbidity

Hospital labour assessment units are prevalent in North America but uncommon elsewhere

\section{WHAT THIS STUDY ADDS}

A formalised approach to care in a hospital labour assessment unit improves women's views of their care and may increase the likelihood of spontaneous vaginal birth

Labour assessment units may want to consider standardising the care provided to include assessment and interventions for maternal psychological state, pain, and positioning

(chair), Shoo Lee, and David Young; members of the Structured Early Labour Assessment and Care by Nurses Trial Group who enrolled participants and collected data-Paula Baker, Amy Hailey, Charlotte Ice, Karen Langston, and Gina Smith (Harris Methodist Fort Worth Hospital, Fort Worth, TX), Nancy Fehr, Lynn Hickey, and Maggie Quance (Foothills Medical Centre, Calgary, AB), Susan Caffrey, Cheryl Hardy, Maggie Hickey, Carol Luppi, and Ginny Silva (Brigham and Women's Hospital, Boston, MA), Judy Claringbold, Jill Fairbairn, Linda McCabe, and Janice McVeety (Ottawa Hospital—Civic Campus, Ottawa, ON), Heather Brown, Jackie Clark, Una Dewtie, Ruth Jordan, Patsy Smith, and Erna Snelgrove (IWK Health Centre, Halifax, NS), Gerry Ashton, Isabelle Baribeau, Janet Britnell, Janet Brownlee, Brenda Cook, Isabelle Gagnon, Adriana Hoselton, Nicole Joly, Debbie Kaye, Ann Salvador, and Julia Watson-Blasioli (Ottawa Hospital—General Campus, Ottawa, ON), Anne Fowler, Lucy Gilmore, Althea Stewart, Debbie Walker, and Linda Young (William Osler Health Centre, Brampton, ON), Luisa Ciofani, Helen Doulos, Francine Martin, Beatrice Stoklas, and Jennifer Supino (McGill University Health Centre, Montreal, QC), Jeannine Alt, Mary Knapp, Sandy Lynne, Denice O'Connor, and Becky VanLaan (Spectrum Health, Grand Rapids, MI), Tania Hansen, Judy Jones, and Teresa Stanfill (St Luke's Regional Medical Center, Boise, ID), Chris Jabaay, Carol Lawrence, Nancy Travis, Kim Vincent (Lee Memorial Health System, Fort Myers, FL), Gaylene Kramchynski, Susan Mussell, and Kris Robinson (St Boniface General Hospital, Winnipeg, MB), Annette McHugh, Glenys Roberts, Louise Taylor, and Grace Thomas (Royal Gwent Hospital, Gwent Healthcare NHS Trust, Newport, Wales), Pat Bielecki, Laurie Lang, Tammi Lothson, Debbie Lunardini, and Robyn Magnuson (Advocate Health Care-Lutheran General Hospital, Park Ridge, IL), Hazel Canavan, Tina Davis-Larkin, Elaine Perkins, Sue Riegel, and Lorian Williams (Advocate Health Care-Christ Hospital, Oak Lawn, IL), Carole England, Jayne Gregory, Debbie Patrick, and Hora Soltani (Derby City General, Derby, UK), Linda Koehl, Marcia Patterson, and Cheryl Stone (Rush University Medical Center, Chicago, IL), Patti Janssen, Monica Nicol, Lynne Palmer, and Lesley Smith (Surrey Memorial Hospital, Surrey, $\mathrm{BC}$ ), and Carol Burke, Joy Grohar, Abby Hornbogen, and Donna Pemberton (Northwestern Memorial Hospital, Chicago, IL).

Contributors: All authors participated in writing the original grant application, were members of the steering committee to manage the trial, and contributed to all drafts of the manuscript. EH was the principal investigator and led the trial team. She contributed to analysing and interpreting the data, wrote the first draft, and is guarantor. AW was the trial statistician and contributed to the data analysis plan and supervision and is guarantor for the analyses. JW was the trial coordinator. During the time of the trial NKL was with the School of Nursing, Oregon Health and Science University, Portland, OR, USA.

Funding: Canadian Institutes of Health Research (grant No MCT59614). Competing interests: None declared.

Ethical approval: Research ethics committees at the University of Toronto and by all participating hospitals.

Provenance and peer review: Not commissioned; externally peer reviewed.

1 O'Driscoll K, Meagher D, Boylan P. Active management of labour: the Dublin experience. London: Mosby, 1993.

2 Oxorn H. Oxorn-Foote human labor and birth. 5 th ed. Norwalk, CT: Appleton and Lange, 1986.

3 Friedman EA, Neff RK. Labor and delivery: impact on offspring. Littleton, MA: PSG, 1987.
4 Chelmow D, Kilpatrick SJ, Laros RK. Maternal and neonatal outcomes after prolonged latent phase. Obstet Gynecol 1993;81:486-91.

5 Wuitchik M, Bakal D, Lipshitz J. The clinical significance of pain and cognitive activity in latent labor. Obstet Gynecol 1989;73:35-42.

6 Lederman R, Lederman E, Work B, McCann D. Relationship of psychological factors in pregnancy to progress in labor. Nurs Res 1979;28:94-7.

7 Cramond W. Psychological aspects of uterine dysfunction. Lancet 1962;2:1241-5.

8 Kapp T.Some psychologic factors in prolonged labor due to inefficient uterine action. Compr Psychiatry 1963;4:9-18.

9 Gardberg M, Tuppurainen M. Persistent occiput posterior presentation-a clinical problem. Acta Obstet Gynecol Scand 1994;73:45-7.

10 Beck N, Siegel L, Davidson N, Kormeier S, Breitenstein A, Hall D. The prediction of pregnancy outcome: maternal preparation, anxiety, and attitudinal sets. J Psychom Res 1980;24:343-51.

11 Crandon A. Maternal anxiety and obstetric complications. J Psychosom Res 1979;23:109-11.

12 Erickson $M$. The relationship between psychological variables and specific complications of pregnancy, labor, and delivery.J Psychosom Res 1976;20:207-10.

13 Watt MC, Stewart SH, Lefaivre MJ, Uman LS. A brief cognitivebehavioral approach to reducing anxiety sensitivity decreases painrelated anxiety. Cogn Behav Ther 2006;35:248-56.

14 Astin JA. Mind-body therapies for the management of pain. Clin J Pain 2004;20:27-32.

15 Stremler R, Hodnett E, Petryshen P, Stevens B, Weston J, Willan A Randomized trial of hands-and-knees position for occipitoposterior position in labor. Birth 2005;32:243-51.

16 Pearl ML, Roberts JM, Laros RK, Hurd WW. Vaginal delivery from the persistent occiput posterior position: influence on maternal and neonatal morbidity. J Reprod Med 1993;38:955-61.

17 Gardberg M, Laakkonen E, Salevaara M. Intrapartum sonography and persistent occiput posterior position: a study of 408 deliveries. Obstet Gynecol 1998 May;91(5 Pt 1):746-9.

18 Rutherford AM. The management of the occipito-posterior position: a prospective study of 145 cases in 1979. NZ Med J 1981;94:419-21.

19 Saunders NJ, Spiby H, Gilbert L, Fraser RB, Hall JM, Mutton PM, et al. Oxytocin infusion during second stage of labour in primiparous women using epidural analgesia: a randomised double blind placebo controlled trial. BMJ 1989;299:1423-6.

20 Menacker $F$. Trends in cesarean rates for first births and repeat cesarean rates for low-risk women: United States, 1990-2003. Natl Vital Stat Rep 2005;54:1-8.

21 US Department of Health and Human Services. Healthy people 2010 Rockville, MD: USDHHS, 2000.

22 Institute for Clinical Systems Improvement. Management of labor. March 2007. www.icsi.org/labor/ labor_management_of_full_version_2.html.

23 Hodnett ED, Lowe NK, Hannah M, Willan A, Stevens B, Weston J, et al. Effectiveness of nurses as providers of birth labor support in North American hospitals. JAMA 2002;288:1373-81.

24 Simkin P, Ancheta R. The labor progress handbook: early interventions to prevent and treat dystocia. Oxford: Blackwell, 1999.

25 Cox J, Holden J. Perinatal psychiatry: use and misuse of the Edinburgh postnatal depression scale. London: Gaskell, 1994.

26 Porter M, Maclntyre S. What is, must be best: a research note on conservative or deferential responses to antenatal care provision. Soc Sci Med 1984;19:1197-200.

27 Hodnett E. Pain and women's satisfaction with the experience of childbirth: a systematic review. Am J Obstet Gynecol 2002;186:S160-72.

28 Brown S, Lumley J. Satisfaction with care in labour and birth: a survey of 790 Australian women. Birth 1994;21:4-13.

29 MedSciNet: Internet Database Solutions. 2008. www.medscinet.se/ $\mathrm{msn} /$.

30 Stephenson J, Imrie J. Why do we need randomised controlled trials to assess behavioural interventions? BMJ 1998;316:611-3.

31 Campbell NC, Murray E, Darbyshire J, Emery J, Farmer A, Griffiths F, et al. Designing and evaluating complex interventions to improve health care. BMJ 2007;334:455-9.

32 Hawe P, Shiell A, Riley T. Complex interventions: how "out of control" can a randomised controlled trial be? BMJ 2004;328:1561-3.

33 Janssen PA, Still DK, Klein MC, Singer J, Carty EA, Liston RM, et al. Early labor assessment and support at home versus telephone triage. Obstet Gynecol 2006;108:1463-9.

34 McNiven PS, Williams JI, Hodnett E, Kaufman K, Hannah ME. An early labor assessment program: a randomized, controlled trial. Birth 1998;25:5-10.

Accepted: 27 June 2008 